\title{
Penerapan Metode Six Sigma dan 5S Untuk Meningkatkan Produktivitas dan Efektivitas Pada Produksi Batako (Studi Kasus UMKM XYZ)
}

\author{
Rahmad Fajri Anasrul \\ Program Studi Teknik Industri, Fakultas Teknologi Industri, Universitas Islam Indonesia \\ Jl. Kaliurang Km.14,5 Sleman, Daerah Istimewa Yogyakarta, Indonesia
}

Email: rahmadfajrianasrul@gmail.com

\begin{abstract}
ABSTRAK
UMKM XYZ merupakan UMKM yang memproduksi bahan bangunan yaitu batako. Penelitian ini bertujuan untuk mengidentifikasi faktor-faktor yang menyebabkan adanya produk cacat dan perbaikan apa yang dibutuhkan pada area tempat kerja. Metode yang digunakan dalam penelitian ini adalah Six Sigma dengan pendekatan DMAIC (Define, Measure, Analyze, Improve, dan Control) untuk peningkatan kualitas dan strategi bisnis yang tidak menghasilkan produk cacat, dan metode 5S (Seiri, Seiton, Seiso, Seiketsu, dan Shitsuke) untuk perbaikan kualitas tempat kerja. Hasil dari penelitian ini menunjukkan bahwa UMKM memiliki total jumlah kecacatan batako sebesar 47 dari 2.135 unit yang terdiri dari cacat retak dan pecah. Dengan jumlah defect per unit yaitu 0,022, defect per million opportunities (DPMO) sebesar 11.000 dalam 1 juta produk batako yang dihasilkan, dan Sigma quality level sebesar 3,79. Kemudian memberi usulan perbaikan kualitas tempat kerja seperti menyediakan tempat penyimpanan alat, peralatan kerja dikelompokkan dan ditempatkan berdasarkan jenis, fungsi, dan ukurannya untuk meminimalkan pemborosan agar meningkatkan produktivitas dan efektivitas dari UMKM.
\end{abstract}

Kata kunci: 5S, DMAIC, Efektivtas, Produktivitas, Six Sigma

\begin{abstract}
MSME XYZ is MSMEs that produces building materials, namely brick. This study aims to identify the factors that cause defective products and what improvements are needed in the work area. This study uses the Six Sigma method with the DMAIC approach (Define, Measure, Analyze, Improve, and Control) to improve quality and business strategies that do not produce defective products, and use the $5 \mathrm{~S}$ method (Seiri, Seiton, Seiso, Seiketsu, and Shitsuke) for workplace quality improvement. The results of this study show that MSME has 47 of the 2,135 units of brick defects. It consists of cracked and damaged defects. The number of defects per unit is 0.022, defects per million opportunities (DPMO) are 11,000 in 1 million brick products produced, and the Sigma quality level is 3,79. Then give suggestions for improving the quality of the workplace so that the existing waste can be minimized so that there is an increase in the productivity and effectiveness of the company. Then provide suggestions for improving the quality of the workplace such as providing a storage area for tools, grouping tools based on function, type, and size in a special place, etc. so that waste can be minimized so that there is an increase in productivity and effectiveness of MSMEs.
\end{abstract}

Keywords: 5S, DMAIC, Effectiveness, Productivity, Six Sigma 


\section{Pendahuluan}

Perusahaan-perusahaan industri di Indonesia kini menyadari akan perubahan orientasi kualitas pelanggan. Perusahaan harus mampu bertahan dan bersaing ketat dengan perusahaan sejenis dalam persaingan industri. Oleh karena itu, perusahaan harus berusaha untuk memenuhi dan mempertahankan kebutuhan pelanggannya. Menurut Ariani dalam (Dewi, 2012), kualitas yang ada pada industri manufaktur harus menekankan tidak hanya pada produk yang dihasilkan, tetapi juga kualitas proses produksi. Padahal, kualitas bukanlah produk akhir, yang terbaik adalah memperhatikan proses pembuatan atau produk yang masih dalam proses sehingga cacat dan kesalahan yang diketahui dapat diperbaiki.

UMKM XYZ merupakan UMKM yang memproduksi bahan bangunan yaitu batako yang terletak di Kecamatan Ujung Batu, Kabupaten Rokan Hulu, Provinsi Riau. Pada UMKM XYZ, pelanggan menginginkan produk batako yang kukuh dan memiliki bentuk yang sempurna, sehingga UMKM XYZ berusaha untuk memenuhi tuntutan kualitas dari pelanggan tersebut. Namun, perusahaan tidak bisa berhenti sampai di situ karena masih ada produk yang sebenarnya tidak memenuhi spesifikasi (defect product). Masalah dalam penelitian ini adalah:

1. Faktor apa saja yang menyebabkan adanya produk cacat?

2. Apa strategi yang dapat dilakukan untuk mengurangi jumlah produk cacat?

3. Apa upaya yang dapat dilakukan agar pelaksanaan $5 \mathrm{~S}$ efektif diterapkan oleh UMKM yang diteliti?

Berdasarkan data yang diperoleh pada UMKM XYZ pada bulan Maret tahun 2021 bahwa hasil produksi batako mengalami kecacatan sebesar 2,2\% dari 2.135 buah batako yang diproduksi. Dari uraian diatas, maka dilakukan penelitian mengenai "Penerapan Metode Six Sigma dan 5S Untuk Meningkatkan Produktivitas dan Efektivitas Pada Produksi Batako". Tujuan dari penelitian ini adalah untuk menemukan faktor-faktor yang menyebabkan terjadinya cacat produk serta saran perbaikannya, dan memberikan rekomendasi perbaikan yang dibutuhkan pada area tempat kerja.

\section{Tinjauan Pustaka}

Metode pengendalian kualitas yang saat ini sedang berkembang adalah Six Sigma. Six Sigma adalah metode peningkatan kualitas berbasis statistik yang membutuhkan disiplin tingkat tinggi dan diterapkan secara luas, menghilangkan akar penyebab masalah dengan pendekatan Define, Measure, Analyze, Improve, dan Control (DMAIC). Six Sigma adalah proses terstruktur yang berfokus pada pengurangan penyimpangan proses sekaligus mengurangi kesalahan melalui penggunaan statistik dan alat pemecahan masalah yang intensif. Metode ini dikenal sebagai metode peningkatan kualitas dan strategi bisnis yang tidak menghasilkan cacat lebih dari 3,4 kesalahan per sejuta peluang (Gupta, 2005).

Menurut Saxena dalam (Indrawijaya, 2010), efektivitas adalah ukuran seberapa jauh suatu tujuan (kualitas, kuantitas, waktu) telah tercapai. Semakin tinggi pencapaian tujuan, semakin tinggi efeknya. Menurut Sutarto dalam (Hayu Kartika, 2011), efektivitas kerja adalah suatu keadaan dimana aktivitas fisik dan mental seseorang dapat mencapai hasil yang diinginkan. Selain efektivitas pekerjaan, keselamatan kerja juga harus diperhatikan. Keselamatan kerja merupakan aspek penting dalam bekerja atau aktivitas kehidupan lainnya (Reno Prasetyo, 2019). Keselamatan kerja merupakan pertahanan diri terhadap segala kemungkinan yang dapat menimbulkan kecelakaan (Rimawan, 2010).

Metode yang digunakan untuk melakukan perbaikan kualitas tempat kerja adalah kaizen. Kaizen berasal dari kata Kai yang berarti perubahan dan Zen yang berarti lebih baik. Setiap orang di perusahaan harus bekerja sama untuk mematuhi tiga aturan dasar untuk menerapkan Kaizen di tempat kerja: penataan, penghapusan, dan standarisasi (Imai, 1998). Meningkatkan kualitas pekerjaan dengan konsep Kaizen yaitu dengan metode $5 \mathrm{~S}$ (seiri, seiton, seiso, seiketsu, dan shitsuke) perlu diterapkan, karena penempatan peralatan di tempat kerja yang tidak teratur sehingga 
membutuhkan waktu yang lama untuk mencari peralatan yang dibutuhkan. Juga, ada banyak item yang tidak diketahui apakah digunakan atau tidak. Dengan penerapan metode 5S diharapkan berbagai pemborosan yang ada dapat diminimalisir dan produktivitas serta efektivitas perusahaan akan meningkat (Osada, 2011).

\section{Metodologi Penelitian}

\section{1 Subjek dan Objek Penelitian}

Subjek dalam penelitian ini adalah UMKM XYZ dan objek penelitiannya adalah produk cacat dan kualitas tempat kerja dari UMKM XYZ.

\section{2 Alur Penelitian}

Berikut merupakan alur pada penelitian ini.

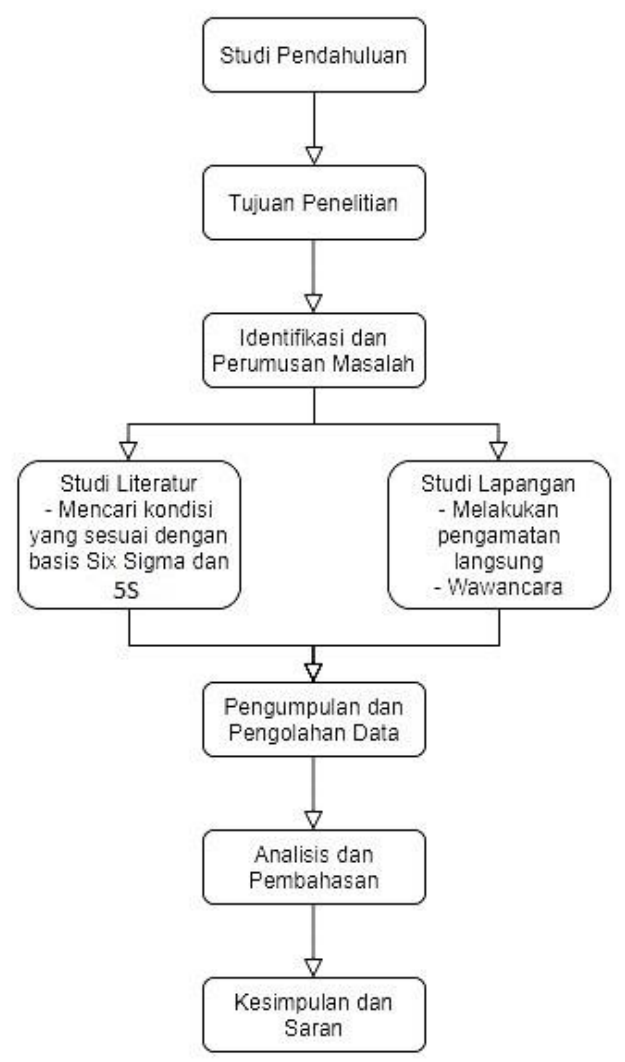

Gambar 1. Alur Penelitian

\section{Hasil dan Pembahasan}

\section{1 Perbaikan Kualitas Produk Menggunakan Metode Six Sigma}

Tahap penerapan dalam meningkatkan kualitas dengan Six Sigma terdiri dari lima langkah, yaitu dengan teknik DMAIC. Berdasarkan hasil analisis lapangan, usulan untuk perbaikan kualitas produk adalah sebagai berikut:

\section{a. Tahap Define}

Pada tahap ini yaitu pendefinisian penyebab produk cacat pada UMKM XYZ, langkahlangkahnya sebagai berikut:

1. Mendeskripsikan proses produksi batako. Proses produksi batako pada UMKM XYZ terdiri dari lima proses utama. Tahapan proses produksi terdapat pada Gambar 2. 


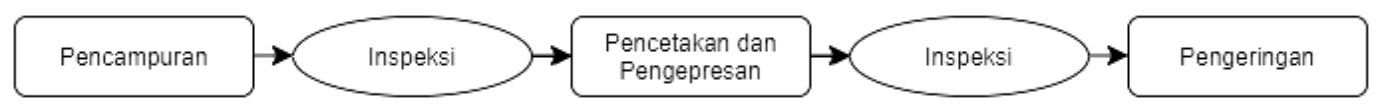

Gambar 2. Alur Produksi Batako

Berikut merupakan penjelasan tiap tahapan proses produksi batako:

- Proses pencampuran (mixing) adalah proses pencampuran antara pasir, semen, dan air. Komposisi yang digunakan untuk membuat batako berukuran 30x15x10 cm adalah 1 sak semen atau $50 \mathrm{~kg}, 5$ gerobak pasir, dan air secukupnya. Komposisi tersebut menghasilkan kurang lebih sebanyak 125 buah batako. Dalam sehari UMKM XYZ bisa memproduksi sebanyak 125 hingga 250 buah batako.

- Proses pencetakan adalah proses yang dilaksanakan apabila pencampuran antara pasir, semen, dan air telah merata, lalu dicetak menggunakan alat pencetak batako. Pada saat adonan batako dimasukkan kedalam cetakan, kemudian dilakukan proses pengepresan menggunakan cangkul dengan cara ditekan kedalam cetakan hingga padat, lalu adonan dilepas dari alat pencetak batako.

- Proses pengeringan merupakan tahapan terakhir dalam proses produksi batako. Proses pengeringan dilakukan selama sehari atau 24 jam dibawah sinar matahari agar mendapat hasil yang bagus. Setelah kering, maka batako bisa disusun dan siap untuk digunakan.

2. Membuat diagram SIPOC untuk melihat proses terkait, urutan proses, interaksi antar proses, dan hal-hal yang berhubungan dengan proses (Gaspersz, 2003). Gambar 3 menunjukkan diagram SIPOC dari proses pembuatan batako.

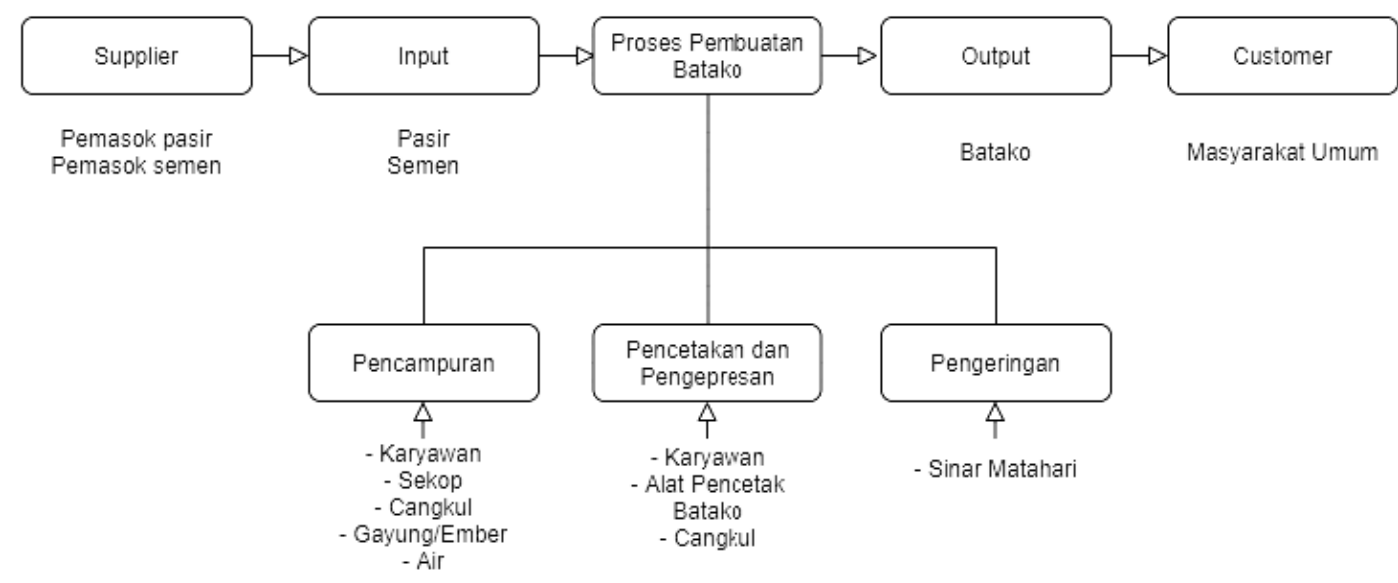

Gambar 3. Diagram SIPOC Produksi Batako

3. Menentukan CTQ atau karakteristik kualitas dari batako. Batako memiliki CTQ yang berfokus pada hasil pencampuran, pencetakan dan pengepresan, dan pengeringan. Tabel 1 menunjukkan CTQ batako, dan Tabel 2 menunjukkan hubungan antara jenis cacat di masing-masing CTQ.

Tabel 1. CTQ Batako

\begin{tabular}{ll}
\hline \multicolumn{1}{c}{ CTQ } & \multicolumn{1}{c}{ Keterangan } \\
\hline Kukuh & Batako memiliki tingkat kepadatan yang kuat \\
Kesempurnaan bentuk & Batako dihasilkan memiliki bentuk fisik yang utuh (tercetak \\
sempurna)
\end{tabular}


Tabel 2. Hubungan Antara Jenis Cacat Di Masing-Masing CTQ

CTQ Jenis Cacat

Kukuh

Cacat retak/keropos

Kesempurnaan bentuk

Cacat pecah/tidak rata

\section{b. Tahap Measure}

Pada tahap ini, pengumpulan data digunakan untuk mengukur kinerja proses sebelum perbaikan berlangsung. Langkah-langkahnya sebagai berikut:

1. Membuat $P$ chart. Saat mengevaluasi dan memahami status proses produksi pada UMKM XYZ, digunakan $P$ chart sebagai diagram kendali. $P$ chart digunakan untuk menentukan persentase produk cacat.

Tabel 3. Data Sampel Batako Bulan Maret 2021

\begin{tabular}{cccc}
\hline No. & Jumlah Sampel & Produk Cacat & Proporsi \\
\hline 1 & 125 & 3 & 0,024 \\
2 & 125 & 2 & 0,016 \\
3 & 250 & 7 & 0,028 \\
4 & 250 & 6 & 0,024 \\
5 & 200 & 3 & 0,020 \\
6 & 240 & 6 & 0,025 \\
7 & 245 & 6 & 0,024 \\
8 & 250 & 6 & 0,024 \\
9 & 225 & 4 & 0,018 \\
10 & 225 & 4 & 0,018 \\
\hline Total & 2.135 & 47 & \\
\hline
\end{tabular}

$$
\begin{aligned}
& \bar{p}=\frac{\sum \text { Produl } \text { Cacat }}{\text { Jumlah Sampel } \mathrm{x} \text { Jumlah Observasi }} \\
& \bar{p}=0,022 \\
& \mathrm{UCL} / \mathrm{LCL}=\bar{p} \pm 3 \sqrt{\frac{\bar{p}(1-\bar{p})}{\mathrm{n}}} \\
& \mathrm{UCL}=0,052 \\
& \mathrm{LCL}=-0,008
\end{aligned}
$$

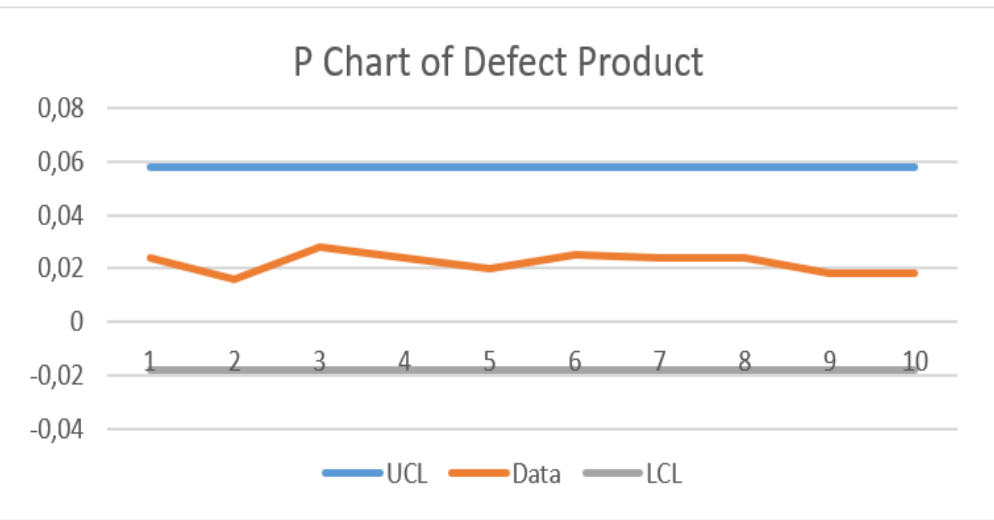

Gambar 4. P Chart of Defect Product 
Berdasarkan Gambar 4, tidak terdapat titik yang melewati UCL maupun LCL, sehingga dapat dikatakan proses produksi terkendali.

2. Menghitung nilai DPMO dan Sigma. Hasil perhitungan DPMO dan Sigma dapat dilihat dibawah ini.

- Defect Per Unit (DPU)"

$$
\mathrm{DPU}=\frac{\mathrm{D}}{\mathrm{U}}=\frac{47}{2.135}=0,022
$$

- Total Opportunity (TOP)

$$
\mathrm{TOP}=\mathrm{U} \times \mathrm{OP}=2.135 \times 2=4.270
$$

- Defect Per Oppportunity (DPO)

$$
\mathrm{DPO}=\frac{\mathrm{D}}{\mathrm{TOP}}=\frac{47}{4.270}=0,011
$$

- Defect Per Million Opportunities (DPMO)"

$$
\text { DPMO = DPO x } 1.000 .000=0,011 \times 1.000 .000=11.000 .
$$

Dari hasil perhitungan di atas, dapat disimpulkan bahwa 1 juta produk batako yang diproduksi oleh UMKM XYZ memiliki probabilitas cacat sebesar 11.000 kali.

- Mengukur tingkatan Sigma

Untuk mengukur tingkat Sigma, dapat menggunakan tabel konversi Sigma, atau masukkan rumus berikut menggunakan Microsoft Excel.

$$
=\text { NORMSINV }((1000000-D P M O) / 1000000)+1.5=3,79
$$

Oleh karena itu, tingkat Sigma yang diperoleh sebelum mengimplementasikan usulan perbaikan adalah 3,79. Level ini digunakan sebagai performa dasar.

Tabel 4. Hasil Rekapitulasi Perhitungan DPMO, Sigma, dan Persentase Cacat Produk

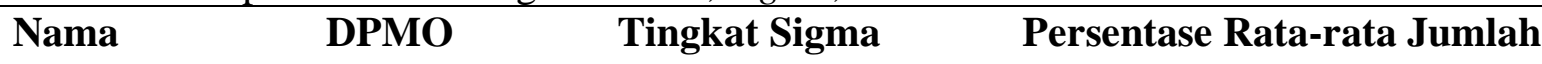
Produk Cacat

$\begin{array}{llll}\text { Batako } & 11.000 & 3,79 & 2,2 \%\end{array}$

\section{c. Tahap Analyze}

Analyze adalah langkah ketiga dalam program peningkatan kualitas Sigma. Langkahlangkahnya sebagai berikut:

1. Diagram pareto. Diagram pareto dibuat untuk menemukan CTQ dengan jumlah kesalahan tertinggi. Diagram pareto pada produk batako ditunjukkan pada Gambar 5.

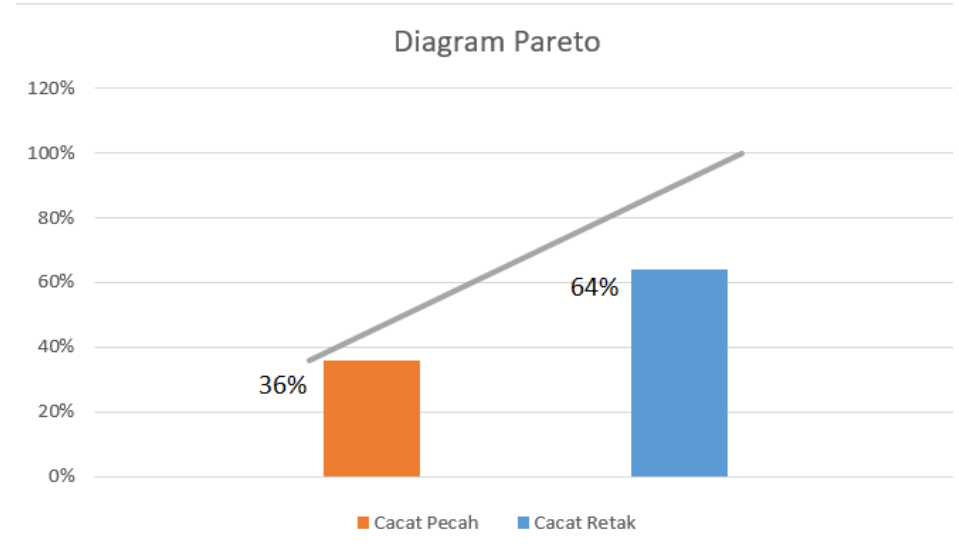

Gambar 5. Diagram Pareto 
Berdasarkan Gambar 5, cacat retak memiliki pengaruh sebesar 64\% dari keseluruhan cacat dimana cacat retak termasuk kedalam CTQ kukuh, sehingga CTQ ini akan menjadi fokus utama dalam perbaikan produk batako.

2. Pembuatan diagram fishbone. Setelah diketahui CTQ yang menjadi fokus perbaikan dari hasil diagram pareto, kemudian menggunakan diagram fishbone untuk mencari penyebab jenis kesalahan yang terjadi. Tahapan penentuan diagram fishbone yaitu:

- Mengidentifikasi masalah awal

- Mengetahui berbagai kategori sebab utama

- Menemukan potensi penyebabnya dengan berdiskusi dengan pihak internal UMKM

- Mengkaji ulang setiap kategori sebab utama

- Menyetujui penyebab yang paling mungkin terjadi

Diagram fishbone dari produk batako ditunjukkan pada Gambar 6 dibawah ini.

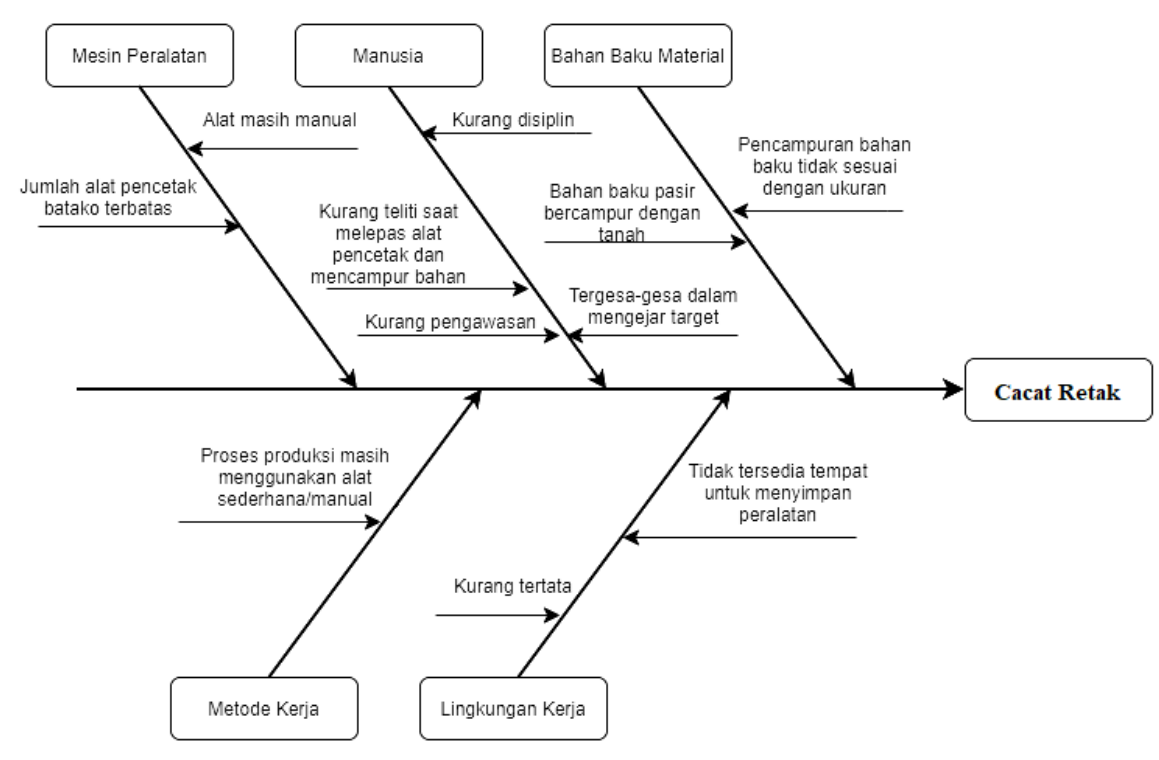

Gambar 6. Diagram Fishbone

Diagram fishbone pada Gambar 6 menunjukkan bahwa cacat retak disebabkan oleh beberapa faktor, antara lain mesin, metode kerja, manusia, lingkungan kerja, dan bahan baku.

\section{d. Tahap Improve}

Tahap ini membahas penyebab masalah yang ditemukan dan dijelaskan dalam tahap analyze. Usulan perbaikan akan dibahas lebih rinci pada tahap keempat ini. Di bawah ini merupakan rekomendasi untuk perbaikan kualitas batako:

1. Mengganti alat pencetak batako yang manual menjadi mesin agar proses produksi semakin cepat dan human error semakin berkurang.

2. Membuat SOP peraturan kerja karyawan agar karyawan lebih disiplin dan rutin melakukan pengawasan, serta membuat SOP proses produksi untuk meningkatkan akurasi proses operasional terutama pada proses pencampuran bahan, pencetakan dan pengepresan.

3. Melakukan perawatan alat secara rutin dan membuat tempat penyimpanan peralatan agar lebih tertata.

4. Area kerja yang diperbaiki dan ditingkatkan lagi untuk mengurangi pemborosan waktu dengan metode $5 \mathrm{~S}$ 


\section{e. Tahap Control}

Tahap control merupakan tahapan akhir dari proses Six Sigma yang berarti seluruh hasil dari tahap improve akan didokumentasikan dan pengimplementasiannya menjadi tanggungjawab kembali kepada pemilik dari UMKM XYZ. Pada tahap ini, prosedur-prosedur serta hasil-hasil peningkatan kualitas dari tahap improve didokumentasikan untuk dijadikan pedoman standar kerja untuk mencegah masalah yang sama terulang kembali. Control adalah fase terakhir dari proses Six Sigma. Artinya, semua hasil dari tahap imrpove didokumentasikan dan pelaksanaannya menjadi tanggung jawab pemilik UMKM. Pada penerapannya, kami mendokumentasikan prosedur peningkatan kualitas dan hasil dari tahap improve dan menggunakannya sebagai pedoman kerja untuk mencegah masalah yang sama terulang kembali.

\section{2 Perbaikan Area Kerja Menggunakan Metode 5S}

Dalam perbaikan area kerja UMKM XYZ, dilakukan menggunakan metode 5S dengan tools audit checklist 5S. Audit checklist 5S berguna untuk mengevaluasi performansi dari implementasi $5 \mathrm{~S}$ yang ada di area kerja, dimana evaluator melakukan penilaian dengan rentang nilai 1 sampai 5 untuk tiap faktor 5S. Berdasarkan hasil audit checklist 5S yang dilakukan, berikut adalah rangkuman nilainya.

Tabel 5. Hasil Audit Checklist 5S

\begin{tabular}{cc}
\hline $\mathbf{5 S}$ & Score \\
\hline Seiri & 2,66 \\
Seiton & 2 \\
Seiso & 2,25 \\
Seiketsu & 2,25 \\
Shitsuke & 2,5 \\
\hline Rata-rata & $\mathbf{2 , 3 3}$ \\
\hline
\end{tabular}

Tabel 5 menunjukkan bahwa nilai rata-rata dari hasil audit checklist 5S masih di bawah nilai 3 (minimum acceptable level). Oleh karena itu, perlu adanya usulan perbaikan terhadap UMKM. Area kerja perlu ditingkatkan untuk mengurangi pekerjaan yang tidak perlu yang memboroskan waktu dengan metode 5S. Berdasarkan hasil analisis, rekomendasi perbaikan dengan 5S adalah sebagai berikut:

Tabel 6. Usulan 5S UMKM XYZ

\begin{tabular}{lll}
\hline \multicolumn{1}{c}{ 5S } & & \multicolumn{1}{c}{ Usulan } \\
\hline Seiri & - & Sebelum mulai kegiatan, kenali benda atau alat yang digunakan pada tempat kerja. \\
(Ringkas) & & Contohnya: kegiatan pengambilan dan pencampuran bahan menggunakan gerobak, \\
& & sekop, cangkul, ember. \\
& - & Sediakan tempat penyimpanan alat sesuai dengan alatnya masing-masing. \\
& - & Simpan alat yang sudah digunakan pada tempat penyimpanan. \\
& - & Buang semua barang dan alat yang tidak terpakai/rusak \\
\hline Seiton & - & Alat-alat dikelompokkan menurut fungsi, jenis, dan ukuran dalam suatu lokasi atau \\
(Rapi) & & kotak alat khusus. \\
& - & Atur peralatan sesuai dengan frekuensi penggunaan. Jika sering menggunakannya, \\
& & dekatkan dengan operator. \\
& - & Produk jadi dan produk setengah jadi perlu dipisahkan \\
& - & Simpan, dan tempatkan produk jadi dengan benar di tempat yang aman \\
\hline Seiso & - & Atur jadwal piket pekerja untuk membersihkan alat dan tempat kerja. \\
Resik) & - & Tempat kerja harus dibersihkan sebelum dan sesudah bekerja. Karyawan \\
\hline & &
\end{tabular}




\begin{tabular}{lll}
\hline \multicolumn{1}{c}{ 5S } & \\
\hline & Usulan \\
\hline Seiketsu & - & Melakukan pemeliharaan dan perawatan alat dan tempat kerja. \\
(Rawat) & - & Membuat SOP (Standar Operasional Prosedur) untuk karyawan. \\
& - & Buat tanda atau petunjuk untuk menyimpan peralatan. \\
& - & Membuat buku checklist yang ditempel ditempat yang tampak kelihatan secara \\
& & langsung oleh karyawan dan pemilik. \\
\hline Shitsuke & - & Biasa lakukan seiri, seiton, seiso, sebelum dan sesudah bekerja. \\
(Rajin) & - & Memastikan peralatan dan sisa bahan yang sudah digunakan tidak berserakan \\
& - & Semua harus bekerja sama dan memperkuat komunikasi untuk saling membantu \\
& & dan mengingatkan agar terbiasa dalam pelaksanaan 5S ini. \\
\hline
\end{tabular}

\section{Kesimpulan}

Kesimpulan dari penelitian ini adalah sebagai berikut:

1. Pada produksi batako, faktor penyebab terjadinya kecacatan adalah proses produksi masih menggunakan peralatan yang sederhana dan tidak tersedia tempat penyimpanan peralatan sehingga menyebabkan kurang terawatnya peralatan yang ada oleh faktor metode dan lingkungan kerja, kurang disiplin, kurang teliti saat melepas alat cetakan, kurangnya pengawasan, dan ketergesaan dalam mengejar target oleh faktor manusia, dan pencampuran bahan baku pasir yang tidak tepat dan tercampur dengan tanah menjadi penyebabnya oleh faktor bahan baku. Dari faktor penyebab tersebut, diberikan usulan perbaikan yaitu mengganti alat pencetak batako yang manual menjadi mesin, membuat SOP peraturan kerja karyawan dan SOP proses produksi, melakukan perawatan alat secara rutin, dan membuat tempat penyimpanan peralatan.

2. Perbaikan area tempat kerja yang dibutuhkan dengan menggunakan metode 5S, yaitu: menyediakan tempat penyimpanan alat dan buang semua barang dan alat yang tidak terpakai/rusak untuk faktor seiri, alat-alat dikelompokkan menurut fungsi, jenis, dan ukuran dalam suatu lokasi atau kotak alat khusus untuk faktor seiton, atur jadwal pekerja untuk membersihkan alat dan tempat kerja untuk faktor seiso, membuat buku checklist untuk mengecek kelengkapan alat, jadwal piket, dll yang ditempel ditempat yang tampak secara langsung oleh karyawan untuk faktor seiketsu, dan yang terakhir memastikan peralatan dan sisa bahan yang sudah digunakan tidak berserakan untuk faktor shitsuke.

\section{Daftar Pustaka}

B. Bregman, B. K. (2005). The TQM Magazine. 19-34.

Dewi, S. K. (2012). Minimasi defect produk dengan konsep six Sigma. Jurnal Teknik Industri, 13 (1), 43-50.

Gasperz, V. (2003). Metode Analisis Untuk Peningkatan Kualitas. PT Gramedia Pustaka Utama, Jakarta.

Gupta, P. (2005). The Six Sigma Performance Hand Book. McGraw Hill, New York, 135.

Hayu Kartika, d. T. (2011). Analisa Pengaruh Sikap Kerja 5S dan Faktor Penghambat Penerapan 5S Terhadap Efektivitas Kerja Departemen Produksi di Perusahaan Sepatu. Program Studi Teknik Industri Universitas Mercu Buana. Jakarta.

Imai, M. (1998). Gemba Kaizen : Pendekatan. Jakarta: Pustaka Binaman Pressindo.

Indonesia, T. R. (2008). Kamus Bahasa Indonesia. Jakarta: Pusat Bahasa Departemen Pendidikan Nasional, 1535.

Indrawijaya, A. I. (2010). Teori, Prilaku dan Budaya Organisasi. Bandung: Refika Aditama, 176.

John S. Oakland, P. M. (1997). Total Quality. Butterworth-Heinemann, Oxford, 85. 
Osada, T. (2011). Sikap Kerja 5S. PPM, Jakarta.

Rimawan, E. (2010). Analisa Penerapan 5S+Safety pada area warehouse di PT Multifilling Mitra Indonesia.

Sugiyono. (2012). Metode Penelitian Bisnis. Alfabeta, Bandung, Cetakan Keenambelas. 